\title{
Análise de aspectos relacionados à sexualidade em site para adolescentes
}

\author{
Giovana Bovo Facchini \\ Ana Cláudia Bortolozzi Maia \\ Ari Fernando Maia \\ Universidade Estadual Paulista, Bauru
}

\begin{abstract}
RESUMO
Este estudo teve o objetivo de analisar o tema da sexualidade em um site destinado à população adolescente como um importante veículo promotor de orientação sexual. Destaca-se aqui a importância de analisar criticamente os conteúdos informativos sobre sexualidade disponíveis em um meio de comunicação como a Internet, atualmente muito difundido entre a população jovem. Para analisar o site, selecionou-se 25 matérias que versavam sobre diferentes temas da sexualidade. Os resultados mostram que os assuntos sobre sexualidade são, em geral, apresentados de forma superficial, não promovem a reflexão e não informam com precisão. Além disso, apresentam uma visão distorcida e preconceituosa, reforçando estereótipos e concepções sexuais vigentes. Conclui-se que é fundamental o posicionamento crítico da Psicologia em relação aos veículos de orientação sexual para que estes possam, de fato, garantir o esclarecimento e a orientação ética e não meramente reproduzir padrões sociais.
\end{abstract}

Palavras-chave: internet; sexualidade; adolescência.

\begin{abstract}
Analysis of sexually related subjects on an adolescent internet site

This study aims at analyzing the sexual subjects on an internet site, intended for an adolescent population, and as a promoter of resources for sexual guidance. It is of importance to analyze critically the context of such resources in communication media such as the internet, which nowadays is available to the young on a worldwide basis. In order to analyze this internet site, 25 sexually orientated subjects were selected. Results show that the sexual subjects are generally presented in a shallow manner and do not inform precisely. Furthermore, they tended to show a distorted vision, full of prejudice, strengthening stereotypes and outdated sexual concepts. It is concluded that a criticpsychological positioning is essential for sexually-related guidance resources, which warrants explanation of content and ethical orientation.
\end{abstract}

Keywords: Internet, sexuality, adolescence.

Dentre os diversos tipos de informação veiculados pelos meios de comunicação e, em especial, pela Internet, encontra-se em grande abundância a questão da sexualidade. Assunto muitas vezes considerado tabu dentro de casa - apesar dos "tempos modernos" é de facilitadíssimo acesso no mundo da informática, sendo frequientemente buscado por jovens, seja para sanar dúvidas ou por pura curiosidade e diversão. Entretanto, diferentemente de outros meios de comunicação em massa, a Internet possibilita que todo e qualquer tipo de informação seja nela veiculada, havendo pouco ou nenhum controle sobre a qualidade do conteúdo que será por ela será exibido. Desta forma, abre-se margem para a transmissão de informações distorcidas, muitas vezes desprovidas de qualquer tipo de embasamento e que poderão influenciar o sistema de valores daqueles indivíduos que com elas entram em contato e, assim, poderão também influenciar a conduta desses indivíduos.

A sexualidade, para efeito da análise, será entendida enquanto um conceito que envolve sobretudo a intencionalidade humana, a expressão e a vivência dinâmica, processual que envolve o crescimento global, condutas sexuais, interrelacionamentos afetivo-sexuais, concepções, atitudes e troca de prazer e cujas manifestações são sociais e históricas (Chauí, 1985; Guimarães, 1995; Maia, 2001; Nunes, 1987; Vitiello, 1995). Essa definição operacional permite observar a ocorrência de vários parâmetros valorativos juntamente às informações que estão disponíveis sobre a sexualidade na internet. $\mathrm{O}$ conceito de sexualidade, entrementes, é amplo, difuso, histórico e essencialmente cultural, não se restringindo, portanto, ao sexo genitalizado. Sendo o conceito de sexualidade historicamente construído, o mesmo torna-se passível de transformações sociais, bem como de questionamentos sobre valores e padrões vigentes socialmente impostos (Maia, 2001). Evidentemente, também as formas como a sexualidade é vivida, experienciada e praticada são histórico-sociais.

Além do conceito de sexualidade, cabe ressaltar também os conceitos de "educação sexual" e "orientação sexual". A educação sexual é um processo 
amplo exercido ao longo do desenvolvimento do sujeito que abrange os aspectos biológicos, psicológicos, sociais e éticos (Ribeiro, 1990; Vitiello, 1995; Werebe, 1981). Acreditamos (Maia, 2001) que a educação sexual deve permitir que o sujeito se situe em relação à sua sexualidade e à sua própria vida, sendo exercida de diversas formas, na escola, na família, por meio de palestras, da mídia, da internet, entre outras possibilidades. $\mathrm{O}$ que diferencia e qualifica a informação, por sua vez, é a maneira como o indivíduo a recebe, ou seja, qual o sentido que ele atribui a tais informações. Então, a partir do momento que estas últimas passam a fazer parte das concepções do sujeito acerca da sexualidade, passarão a direcionar suas ações, promovendo mudanças de atitude em relação à sua sexualidade e à de outras pessoas que fazem parte de seu meio, sendo que tais modificações podem ocorrer tanto em um sentido positivo quanto em um negativo.

A educação sexual está envolvida no processo de educação geral que, mesmo sem ser completamente consciente, permeia todo o comportamento humano. A informação faz parte do processo geral da educação sexual, mas não é apenas isso. Vitiello (1995) esclarece que a educação sexual engloba o ato de "informar", "orientar" e "aconselhar", mas é um processo que não pode ser restrito a nenhuma dessas atitudes.

A sexualidade do adolescente é compreendida como vinculada às variáveis biológicas, sócioculturais e psicológicas que o influenciam (Loyola, 1990). É uma fase de transição em que se atinge a maturidade biológica e sexual, define-se a identidade sexual e, potencialmente, define-se também o espaço social de homem ou mulher. A puberdade é um fenômeno universal, mas a adolescência é cultural uma vez que depende de influências históricas e sociais (Becker, 1994; Costa, 1986).

O componente orgânico da adolescência é o período da puberdade, a qual corresponde a mudanças físicas, crescimento e amadurecimento sexual e desenvolvimento das características sexuais secundárias em meninos e meninas. Tais mudanças às vezes diminuem a auto-estima do jovem, bem como geram uma ansiedade que é decorrente, entre outros aspectos, do medo de não se conseguir, fisicamente, atingir o padrão socialmente imposto e aceito. Para os garotos, este medo se relaciona ao desempenho, ou seja, a não se conseguir concretizar o coito, enquanto nas meninas ele recai sobre a atratividade sexual, isto é, à efetividade dos jogos de sedução por elas realizados com a finalidade de se conseguir conquistar a pessoa que deseje manter relações com ela. Alguns aspectos são válidos para ambos os sexos, como a necessidade de pertencerem e se sentirem aceitos em um grupo de iguais e as desavenças com os genitores enquanto uma forma de auto-afirmação (Becker, 1994; Campos, 1986; Loyola, 1990; Vitiello, 1997).

Entretanto, deve-se ressaltar que essas características não são regra geral, estando associadas, como já foi mencionado, a variáveis sócio-culturais e biopsicológicas. É sabido que na adolescência há muita curiosidade e ânsia de informações sobre sexualidade. Ainda que existam, atualmente, muitas informações disponíveis, em geral, os adolescentes ainda recorrem a fontes não muito confiáveis ou a colegas adolescentes, igualmente desinformados. Há também um outro aspecto da questão: talvez a informação oferecida seja parte dos meios pelos quais se exerce a repressão social sobre a sexualidade.

Outra questão importante diz respeito aos papéis sexuais. Os processos por meio dos quais a criança pensa em si própria como pertencente ao gênero masculino ou feminino são culturais, sendo que a cultura sempre irá tentar "naturalizar" certos padrões que, na maioria das vezes, buscam atender aos interesses de classes sociais ou grupos dominantes (Whitaker, 1995). As diferenças orgânicas que indicam o gênero a que pertencemos são modeladas pela cultura, englobando-se aí todo um conjunto de símbolos, valores e práticas que influenciam o comportamento humano também nos seus aspectos sexuais (Azeredo, 1993; Fucs, 1998; Grossi, 1992; Paiva, 1989; Silva, 1999; Whitaker, 1995).

Para Whitaker (1995) a primeira instância socializadora do ser humano é a família e a segunda é a escola. Em ambas as instituições, parece que as diferenças sexuais vão sendo estabelecidas, reforçadas e reproduzidas, no caso como estereótipos, caracterizando-se como "sub-culturas". Assim a cultura, que se constitui em um conjunto de símbolos, valores e práticas que visam modelar a conduta humana, em nossa sociedade burguesa, não é um patrimônio coletivo e, segundo a autora “(...) articula as várias subculturas, privilegiando práticas e conteúdos das classes sociais dominantes ou dos grupos mais poderosos (...)" (1995, p. 32). Os papéis sexuais, estabelecidos pela cultura como atributos estereotipadamente próprios de homens e mulheres são, de certa forma, mecanismos que reforçam a repressão sexual.

Vários autores têm discutido a questão da repressão sexual na história e na atualidade (Cabral, 1995; Canella, 1984; Chauí, 1985; Nunes, 1987; Ribeiro, 1990). É preciso reconhecer que a repressão encontra-se associada a regras social e culturalmente impostas em um determinado momento histórico. Portanto, a partir do momento em que se fala em seguir uma normatização que atenda às expectativas de uma determinada sociedade, tem-se uma forma de repressão com regras que referem-se a proibições ou permissões. No que concerne à repressão sexual propriamente dita, segundo Chauí (1985), ela pode ser considerada como:

(...) um conjunto de interdições, permissões, normas, valores, regras estabelecidas histórica $e$ culturalmente para controlar o exercício da sexualidade, pois (...) o sexo é encarado por diferentes sociedades (e particularmente pela nossa) como uma torrente impetuosa e cheia de perigos (...). A repressão aparece, assim, como ato de domínio e dominação e o reprimido como submissão à vontade e à força alheia - como que uma alienação (pp. 9-13). 
A definição acima implica alguns esclarecimentos: de fato a repressão pode ser entendida como um conjunto de processos de restrição, coerção e supressão de determinados impulsos. Estes são historicamente modificados, uma vez que as condições pelas quais são satisfeitas as necessidades humanas, incluindo as sexuais, são histórico-sociais. Os processos de repressão são tanto sociais quanto individuais e, no indivíduo, são tanto conscientes quanto inconscientes. Sumariando a questão, sempre que se fala de repressão há a necessidade de esclarecer as relações histórico-sociais entre indivíduo e cultura para poder caracterizar o modo como os mecanismos de repressão sexual operam na cultura e no indivíduo.

Segundo Marcuse (1956/1968) a sociedade capitalista em seu desenvolvimento moderno se caracteriza por um crescente processo de racionalização, que pode ser desejável na produção de bens e na administração, mas é nocivo em processos que envolvam atividades formadoras, educativas, uma vez que essas são fundamentalmente subjetivadoras, isto é, são constituintes da subjetividade dos indivíduos. As novas formas de controle social, engendradas a partir de meados do século passado, utilizam a tecnologia para reprimir a emergência de necessidades ligadas à liberdade e oferecer objetos que satisfazem as necessidades compatíveis com os processos de dominação e reprodução social. Nesta sociedade a repressão é percebida como liberdade! Como compreender a repressão se, aparentemente, nunca houve tanta liberdade sexual?

Novamente Marcuse (1956/1968), fazendo uma leitura filosófica do pensamento de Freud, aponta questões importantes. Embora, segundo Freud, toda civilização seja de algum modo repressiva, os conceitos freudianos não diferenciam as dimensões biológica e social. Marcuse (1956/1968) elabora dois conceitos que apontam especificamente para a dimensão histórico-social: o conceito de maisrepressão, indicando as restrições requeridas pela dominação social e o conceito de princípio de desempenho indicando a forma histórica predominante do princípio de realidade. A possibilidade de oferecer informações sobre a sexualidade que não reproduzam formas de maisrepressão e que não coadunem com o princípio de desempenho vigente implica, ao mesmo tempo, informar e proporcionar condições para questionar as formas sociais de repressão e de gratificação relacionadas à sexualidade, respeitando em alguma medida as inclinações indivíduais, já que a sexualidade teria um componente essencialmente "associal". O sentido desse componente é esclarecido por Marcuse (1965/1998):

O conflito entre o princípio do prazer e o princípio de realidade é dirigido por meio de uma liberalização controlada, que realça a satisfação obtida com aquilo que a sociedade oferece. Mas nessa forma de liberação a energia libidinal muda sua função social: na medida em que a sexualidade é sancionada e até encorajada pela sociedade (...) ela perde a qualidade que, segundo Freud, é sua qualidade erótica essencial, a saber, o elemento de emancipação no que se refere ao social. Era nessa esfera que habitava a liberdade ilícita, a perigosa autonomia do indivíduo sob o princípio do prazer: sua limitação autoritária por parte da sociedade testemunhava a profundidade do conflito entre indivíduo e sociedade, ou seja, em que extensão a liberdade era reprimida. Agora com a integração dessa esfera ao campo dos negócios e dos divertimentos, a própria repressão é recalcada: a sociedade não ampliou a liberdade individual, e sim o seu controle sobre o indivíduo (p. 106).

Uma orientação sexual, adequada, ética e eficaz para um processo saudável de educação sexual deve, portanto, ir além da transmissão de informações; deve visar uma conscientização do sujeito sobre sua própria condição e sobre sua sexualidade, o que, por um lado, implica sem dúvida uma crítica social e, por outro, mudanças de valores e superação de preconceitos e estereótipos. Neste cenário, considerando que a Internet é, potencialmente, tanto um veículo promotor de orientação sexual quanto um veículo para a repressão sexual, nos propusemos a analisar algumas publicações em um site voltado para o público feminino que trata da questão da sexualidade. Acreditamos que dever-se-ia oferecer textos que não se restringissem à mera transmissão de informações, mas sim, que promovessem questionamentos e reflexões acerca dos padrões de comportamento socialmente instituídos, buscando-se assim uma superação de preconceitos e estereótipos e a vivência de uma sexualidade mais livre. Para elucidar esta questão este estudo tem o objetivo de analisar o tema da sexualidade em um site para adolescentes.

\section{MÉTODO}

Para analisar as questões da sexualidade na internet escolhemos como objeto de análise o web site http://www.igirl.com.br, que trata de questões diversificadas como sexo, moda, astrologia, beleza e sexualidade, sendo esta última a que ocupa maior "espaço" no site. O objetivo do site é oferecer esclarecimentos gerais e eliminar as dúvidas mais comuns de adolescentes que enviam questões por $e$ mail sobre todos os temas. Para isso, no caso da sexualidade, o site se propõe a fornecer artigos sobre diferentes assuntos, versando sobre os aspectos anátomo-fisiológicos e psicológicos da sexualidade humana de forma a proporcionar esclarecimentos, diversão e entretenimento.

Optou-se por fazer uma análise de conteúdo, conforme esta foi definida por Bauer e Gaskell (2003), considerando que este procedimento pode ser articulado ao referencial teórico e se refere tanto ao emissor quanto ao público, ou seja, permite elaborar uma crítica ao emissor e também dá pistas sobre o perfil do público a que se dirige. A análise privilegiou a dimensão semântica, isto é, foram destacados os sentidos (conotativo e denotativo) dos textos. A dimensão sintática, que privilegia o como se diz algo não foi destacada, considerando que seria necessário tangenciar questões que dizem respeito à própria internet e às características de um texto nesta mídia. 
Dentre as diversas matérias disponíveis no site, foram selecionadas 25 que tratavam da sexualidade, sendo que estas versaram sobre os seguintes assuntos: orgasmo, virgindade, masturbação, homossexualidade, sexo anal, métodos contraceptivos, doenças sexualmente transmissíveis (DSTs), comportamento, papéis sexuais, prazer etc. As matérias que apresentavam outros temas, que não a sexualidade, foram descartadas para análise. Considerou-se que esta amostra era representativa por abranger várias formas de conduta sexual e várias orientações sobre a sexualidade. Em cada matéria os temas foram agrupados por assuntos relacionados a eixos temáticos previamente estabelecidos.

\section{Resultados e Discussão}

O site aqui analisado contém diversos artigos, os quais se encontram absolutamente dissociados uns dos outros, ou seja, não existe um continuum entre os conteúdos das diferentes matérias. Isso provoca uma fragmentação do conteúdo geral da sexualidade, sendo que os diferentes tópicos a ela relacionados são colocados como assuntos estanques, fechados sobre si mesmos, desconectados de outras temáticas que, na verdade, acrescentam elementos umas às outras. Além disso, o fato das matérias serem escritas por pessoas diferentes, com visões de mundo diferentes e bagagens conceituais igualmente diferentes, faz com que algumas informações contidas em um dado artigo entrem em contradição com aquelas observadas em outro. Isso não é ruim em si mesmo, apenas indica que, no lugar da discussão das próprias contradições entre as várias visões vigora a fragmentação. Outra observação é que além do acesso a sites não se constituir necessariamente uma prática assídua, nada garante que uma pessoa que tenha lido uma das matérias lerá as outras, o que favoreceria a elaboração de concepções incompletas e fragmentárias.

Nos artigos referentes à questão da virgindade, alguns abordam, adequadamente, que esta não se encontra relacionada somente com a ruptura de uma membrana, mas sim, com o início da vida sexual dos parceiros (carícias íntimas, sexo oral, sexo anal, masturbação), enquanto outros, por sua vez, tratam a questão sob um ponto de vista mais biológico, colocando a perda da virgindade associada à perda do hímen. Esta análise pode ser evidenciada nos seguintes trechos:

É muito comum meninas terem medo de perder a virgindade ou se machucar se masturbando, mas essa idéia deve ser deixada de lado. A virgindade está ligada ao ato sexual com outra pessoa e à penetração. A pelinha que fica na entrada da vagina - o hímen - pode se romper durante a masturbação se algum objeto for introduzido na vagina. $O$ dedo, no entanto, não tem o diâmetro necessário para que isso aconteça. (Masturbação Feminina)

Algumas meninas resistem em fazer sexo vaginal para manter a virgindade - ou melhor, para manter o hímen, aquela pelinha que fica na entrada da vagina e que é rompida quando há penetração. Tem gente que, inclusive, para continuar 'virgem', prefere outras práticas, como sexo oral ou mesmo sexo anal (...). (A virgindade e o sexo anal)

É importante lembrar que o que muda de fato na vida da menina depois de perder a virgindade é o modo como ela se relaciona com os outros e com ela mesma e não o rompimento de uma membrana. Às vezes, a atenção dada à virgindade física é exagerada e algumas meninas chegam a trocar todos os tipos de carícias com o namorado, mas não topam transar só para se manterem virgens. (Os grilos da primeira vez)

No que tange à questão dos métodos contraceptivos e doenças sexualmente transmissíveis (DSTs), a desconexão entre os artigos também se encontra presente, proporcionando, da mesma forma, uma visão distorcida e incompleta acerca dos temas abordados. Assim, enquanto um dos artigos faz menção apenas a como se usar corretamente a camisinha, inclusive com fotos ilustrativas, outro relaciona o uso do preservativo - e de outros métodos contraceptivos - com a prevenção de uma gravidez indesejada e de doenças sexualmente transmissíveis, embora isto seja realizado de forma superficial. Além disso, um dos artigos coloca o coito interrompido e a tabelinha enquanto métodos contraceptivos "pouco confiáveis". Ainda que o texto considere, adequadamente, a fragilidade dessa prática para a contracepção, entendemos que tendo-se em vista a população para a qual o site se destina, que é de adolescentes, esse comentário pode ser inadequado. Sabemos que os jovens, em geral, têm o chamado "pensamento mágico", que é a fantasia de que as coisas nunca irão acontecer com eles, sendo por esta razão que métodos como os acima mencionados deveriam ser enfaticamente desencorajados e nunca deveriam ser usados na prevenção de uma gravidez indesejada e não somente serem classificados como "pouco confiáveis". Os aspectos acima mencionados podem ser vistos nos trechos que se seguem:

Além de certificar-se de que o preservativo é de boa qualidade (...) a melhor forma de evitar que a camisinha fure ou estoure é colocá-la corretamente. Para isto, a embalagem deve ser aberta com as mãos - sem usar os dentes ou uma tesoura, que pode perfurar o látex do preservativo - e a camisinha deve ser colocada no pênis já ereto. (Contratempos da transa - a camisinha estourou)

(...) é sempre bom lembrar: o único jeito seguro de evitar as doenças sexualmente transmissíveis (DSTs) é usar a camisinha! (Métodos contraceptivos)

O coito interrompido é quando o menino tira o pênis da vagina antes de ejacular. Este método não é muito confiável porque o garoto pode demorar para tirar o pênis ou pode haver saída de esperma antes da ejaculação. (Dez mitos sobre gravidez) 
(...) a tabelinha não é muito confiável. A pílula e a camisinha são métodos contraceptivos mais seguros. (Dez mitos sobre gravidez)

$\mathrm{O}$ site também proporciona elementos para a análise das expectativas que se costuma criar em torno do desempenho sexual masculino. Um artigo que trata especificamente da ejaculação precoce procura suas causas e como o garoto pode remediar uma situação já instalada, mas em nenhum momento aborda a construção histórica, social e cultural relacionada a estas expectativas criadas em torno do homem, às quais referem-se ao fato de que uma vivência feliz da sexualidade só pode ser encontrada em uma relação em que o coito seja concretizado, por um determinado período de tempo. Assim, quando se fala em causas sem realizar uma reflexão acerca de aspectos como os anteriormente mencionados, acabase por promover uma culpabilização do jovem leitor, como ilustrado abaixo:

[para evitar a ejaculação precoce] o ideal é tentar controlar a ansiedade - que pode ser provocada por inúmeros fatores - medo de não conseguir manter a ereção, inexperiência sexual e medo de ser pego por alguém. (...) Para relaxar e conseguir levar a transa adiante, quem sofre deste problema deve evitar ficar pensando na própria performance durante a transa - o que aumenta o nervosismo - e procurar se concentrar mais na parceira, curtir cada momento. (Contratempos da transa - Ejaculação Precoce)

Inúmeros são os motivos que fazem um menino falhar na hora H. Pode ser falta de concentração, alguma lembrança que o desestimule, inexperiência ou até mesmo falta de interesse na garota (essa não é uma regra). O excesso de álcool ou o uso de algumas drogas também podem comprometer a excitação do garoto. (Contratempos da transa - $\mathrm{O}$ menino brocha)

Aliás, o aspecto da culpabilização permeia grande parte das matérias do site, colocando sempre para os adolescentes, em tons de conselhos ou dicas, que eles devem procurar relaxar frente a qualquer dificuldade, que a ansiedade e o nervosismo são "coisas da sua cabeça" e que, portanto, só cabe a eles solucioná-las. Assim, acaba-se por jogar sobre as costas do adolescente a responsabilidade de superar suas preocupações para que tudo corra perfeitamente bem em sua vida sexual. A sociedade repressiva sai ilesa nos textos do site analisado. Aspectos como estes podem ser observados nos seguintes trechos de matérias retiradas do site:

[para não sentir dor na penetração] procure relaxar, curta as preliminares e só parta para a penetração quando sentir que está excitada o suficiente para isso. (Contratempos da transa - A menina sente dor na penetração)

É bom que o menino e a menina tenham bem claro o que agrada, o que dá prazer. Conhecer o parceiro e suas vontades é fundamental. Outra coisa importante é estar à vontade, é praticamente impossível que uma menina que está tensa chegue ao clímax. (Contratempos da transa - A menina não atinge o orgasmo)

(...) chegar ao orgasmo. É essencial que não só seu corpo esteja excitado, mas que você também esteja relaxada para se deixar sentir prazer. (Orgasmo feminino)

Quanto às matérias que versam sobre o orgasmo feminino e o Ponto $\boldsymbol{G}$, pode-se verificar a constante preocupação destas em propor possíveis causas associadas ao insucesso de uma mulher em conseguir atingir orgasmos e formas de superar estas causas. Mais uma vez pode-se identificar a questão da culpabilização, como ilustram os trechos abaixo transcritos:

Não conseguir chegar ao orgasmo é um problema de fundo psicológico, na maioria das vezes. Geralmente é conseqüência de uma primeira vez. traumática (a mulher sentiu dor, o parceiro foi agressivo e pouco carinhoso). Mas também pode ser uma visão distorcida da sua sexualidade. (Contratempos da transa - A menina não atinge o orgasmo)

O segredo para ter uma relação sexual legal é se soltar, relaxar e conhecer o próprio corpo. (...) não ache que o parceiro é que vai saber como fazer tudo para que você se excite, mas você mesma pode experimentar sozinha o prazer antes de ter relações sexuais. Masturbar-se e se tocar podem ser maneiras legais de conhecer a si mesma. (Orgasmo feminino)

A posição ideal para atingir o Ponto G é de cócoras ou sentada. Deitada não é indicada, porque assim ele desaparece. Não adianta achar que é só seguir o mapa. Para que ele seja atingido, a mulher precisa estar relaxada, as paredes vaginais têm de estar muito lubrificadas e o homem precisa se sentir confiante e descontraído na relação para que seu pênis se movimente à vontade dentro da vagina. $O$ prazer feminino não é tão simples quanto o masculino, é necessário saber explorá-lo e não ter pressa, ir se conhecendo para se descobrir. (Ponto G)

Não se está tentando, com esta análise, afirmar que atingir ou não o orgasmo independa de fatores de fundo psicológico. Sabe-se que em um grande número de casos, é realmente isto o que acontece. No entanto, os artigos não passam pela questão mais importante: por que se deve, necessariamente, chegar ao orgasmo? Será que não é possível ter uma vida sexual plenamente satisfatória, buscando-se outras alternativas de busca do prazer? O orgasmo é colocado como obrigação para uma relação sexual feliz e, de fato, concretizada. As mulheres têm encarado o não atingir o orgasmo como sinônimo de uma relação sexual incompleta, como se ele fosse o "encerramento de um espetáculo", e isso é resultado 
de uma poderosa repressão sexual, daquela que age "para o sim", ao nível das permissões, e não das proibições (Chaú, 1985). No que se refere à questão específica do Ponto G, além das análises anteriores, as quais são igualmente válidas, deve-se destacar o caráter de mistério que ronda em torno do "poderoso" ponto:

Você já deve ter ouvido falar do famoso ponto $G$. Aquele que faz a menina ter um grande prazer. Mas como um monte de meninas, não faz idéia de onde ele se esconde. E muito menos [se pode] ter certeza de que ele não seja uma lenda. Por esse motivo, o iGirl foi desvendar esse mistério! (Ponto G)

Assim, o Ponto G vem colocar mais uma obrigação para se ter uma relação sexual perfeita: não basta mais ter um orgasmo; o que as mulheres buscam agora são orgasmos múltiplos, tão intensos como elas nunca puderam imaginar, bem como o tal ponto que os proporcionará. E cria-se, assim, mais uma forma de repressão sexual, baseada na idéia de que mais (orgasmos mais intensos, em maior número) é melhor, ou seja, na idéia de que o desempenho sexual pode ser medido quantitativamente. $\mathrm{O}$ artigo que trata do Ponto $\mathrm{G}$ e aqueles que tratam de temáticas como masturbação, orgasmo, até colocam que a busca de prazer é uma forma de aprendizado, que se deve buscar conhecer o próprio corpo para descobrir aquilo que agrada e aquilo que não proporciona prazer. Entretanto, este autoconhecimento não é colocado enquanto uma forma saudável de se buscar aprender suas próprias formas de obtenção de prazer, mas sim, como algo necessário para aprender a sentir o prazer imposto pela sociedade, ou seja, o orgasmo, os orgasmos múltiplos, o Ponto $\mathrm{G}$ que proporcionará orgasmos múltiplos e fantásticos, e assim por diante. Um exemplo do que se afirma nessa análise pode ser visto no trecho:

Não conseguir chegar ao orgasmo é um problema de fundo psicológico (...). Mas também pode ser uma visão distorcida da sua sexualidade. Orgasmo é descoberta e aprendizado, você precisa aprender onde sente mais tesão e aprender a estimular estes pontos. (Contratempos da Transa - A menina não atinge o orgasmo)

Parece que a constante necessidade de se criar novas necessidades que caracteriza o panorama atual capitalista atingiu também a esfera sexual, que como se sabe, constitui-se em um filão do mercado atual, com seus livros de receitas práticas (para se conseguir um homem, para se atingir um orgasmo, com inúmeras novas posições para se alcançar aquele prazer nunca antes conseguido, entre muitos e muitos outros), seus livros de auto-ajuda para aqueles que possuem uma vida sexual infeliz, revistas que se dedicam quase exclusivamente aos referidos temas, programas de televisão etc.

A concepção de adolescência que permeia as matérias do site também se constitui em objeto de análise. Nele, a adolescência é tomada como sendo um fenômeno universal, o que promove uma visão estereotipada da mesma como uma fase da vida permeada por conflitos, necessidade de transgressão (principalmente frente aos pais), rebeldia etc. Entretanto, como sabemos, o fenômeno da adolescência é cultural (Becker, 1994; Costa, 1986, Loyola, 1990), sendo que a visão adotada pelo site é extremamente classista, ou seja, coloca como homogêneos processos que se verificam somente entre os adolescentes médioburgueses, desconsiderando a existência de muitos adolescentes pobres do país que não têm acesso à educação, a bens materiais, condições dignas de vida e cujas condições sociais lhes impõe assumir responsabilidades da vida adulta, como o trabalho. Esta reflexão pauta-se em uma leitura geral e abrangente de todo o site, sendo que uma das passagens que pode ilustrar este fato encontra-se na seguinte citação:

Este tipo de comportamento ["ficar" com vários garotos] é encontrado com freqüência na adolescência, quando os hormônios estão a mil e a vontade de conhecer pessoas e ter experiências inéditas chega a ser maior do que a preocupação com o que as pessoas vão dizer. (Fama de galinha)

Quanto à possibilidade de ser homossexual (...) outras meninas o fazem para transgredir as normas da família numa fase de rebeldia. Há ainda as que são levadas a isso para fazer parte de um grupo. (Especial lesbianismo: da descoberta à aceitação)

Outro ponto aqui ressaltado diz respeito à questão da homossexualidade. Em todo o site há uma tendência a considerar somente o relacionamento heterossexual; a única manifestação contrária aparece quando há o destaque para o tema em matérias que versam especificamente sobre esse assunto. Quando tratado no site, o tema da homossexualidade reflete questões importantes e adequadas, mas não faz um aprofundamento, especialmente discutindo sobre o preconceito e a discriminação, tão comum entre os jovens. Desta forma, há uma carência de informações e o tema é tratado de maneira geral. Por exemplo, o trecho abaixo transcrito faz um breve esclarecimento sobre a homossexualidade, mas não promove a reflexão para além disso:

Homossexual é aquele que desenvolve atração afetiva e sexual por alguém do mesmo sexo. Como não mandamos nos nossos desejos, não escolhemos sentir atração por determinado sexo. $O$ que podemos escolher é vivenciar ou não o desejo que sentimos. (Sou homossexual?)

Ainda no que concerne a este assunto, a "causa" da homossexualidade não é posta, nas matérias do site, como uma doença, o que é muito pertinente. Pelo contrário, nega-se isso categoricamente, esclarecendo que na literatura ainda não há consenso sobre essa questão. Entretanto, quando busca causas para a homossexualidade, de alguma forma associa-se a 
questão a algo que pode ser prevenido, patologizandose a questão. Além disso, apresenta a informação da resolução do Conselho Federal de Psicologia de forma incorreta, pois esta afirma que é vedado aos psicólogos tratar a homossexualidade como doença, propondo tratamento, e de se manifestarem em meios de comunicação de massa disseminando preconceitos contra homossexuais. A resolução é atual, embora a homossexualidade tenha sido suprimida do CID (Catálogo de Doenças Internacionais) há 30 anos. Esta análise pode ser verificada abaixo:

(...) O desenvolvimento da sexualidade depende da interação de fatores biológicos, psicológicos e sociais. O Conselho Federal de Psicologia já apresentou uma resolução que exclui a possibilidade da homossexualidade ser uma doença. (Sou homossexual?)

Vários são os fatores que podem explicar a personalidade homossexual - hormônios, genes, figuras dos pais etc - mas a verdade é que até hoje ninguém conseguiu comprovar porque os homossexuais são homossexuais. (Especial lesbianismo: da descoberta à aceitação)

Em outra passagem, é possível perceber que o texto atribui à homossexualidade uma condição de rebeldia, contrariando a idéia de "condição" e não esclarecendo ao leitor a diferença entre comportamento homoerótico de uma condição de fato, afetivo-sexual homossexual.

Se você já pensou ou pensa nisso [lesbianismo], fique atenta para não fazer algo só para se sentir transgressora e moderna, ou mesmo para chamar a atenção dos garotos (que, já se sabe, em sua maioria adoram observar duas meninas juntas) $e$ correr o risco de depois se arrepender. (Meninas que beijam meninas)

De maneira geral, quando as matérias não tratam especificamente de uma relação homossexual, acabam trazendo sempre uma visão idealizada de relacionamento, a saber, um relacionamento heterossexual, como ilustram as passagens abaixo, por exemplo:

A falta de excitação (...) é a maior responsável pela ausência de lubrificação. Para isso não acontecer, a menina e o menino devem investir mais nas preliminares para que a vagina da garota fique 'pronta' para a penetração. (Contratempos da transa - Falta de lubrificação na vagina)

Não é algo errado transar com o garoto na primeira ficada, é só uma questão de escolha sua. Também não é nenhuma obrigação transar só porque você ficou com o garoto - e ele quer. (Transar na primeira ficada)

Outro ponto que deve ser aqui analisado é o reforço do estereótipo da mulher submissa, passiva $\mathrm{e}$ que dirige todas as suas "armas sexuais" na direção da conquista de um homem. Esta visão permeia grande parte das matérias do site, as quais não discutem o processo que resultou em comportamentos tão diferenciados entre homens e mulheres, naturalizandoos. Desta forma, impossibilita uma reflexão acerca do tema que possa promover uma superação desta condição inferior por parte das mulheres. Pelo contrário, exibem em seus artigos comportamentos que as meninas devem assumir para conquistar os garotos.

A pior parte de ganhar a fama de galinha aparece quando algum gatinho conquista de verdade o coração da menina. Ela quer se entregar de corpo e alma para o menino, investir no namoro e ficar só com ele, mas se ele for da mesma turma que ela, do mesmo bairro ou escola, ser considerada uma galinha pode se tornar um sério problema na vida da garota. (Fama de galinha)

A primeira coisa que você precisa fazer é entender como o menino beija. Assim, você segue o mesmo ritmo que ele. (Dicas para o primeiro beijo)

Para ajudar as garotas que querem chegar no gatinho, mas que ainda não sabem direito o que fazer, o iGirl desenvolveu um guia prático de como abordar um menino que você não conhece, mas que está paquerando. Grande parte das sugestões foi dada por aqueles que mais nos interessam: os meninos. (Guia prático da paquera)

(...) a menina tem que jogar um charme, ser engraçadinha, mas sempre deixar uma dúvida do que está rolando. (...) Também é preciso tomar cuidado para a ousadia não virar vulgaridade. (Guia prático da paquera)

(...) fizemos uma pesquisa de utilidade pública (...). $O$ objetivo era saber o ranking das coisas que eles mais odeiam. (O que eles odeiam que a gente façaParte I)

(...) ouvir o tão querido sexo oposto sempre ajuda a entender as conseqüiencias de algumas manias femininas que nem sempre percebemos que incomodam (ou magoam) tanto. (O que eles odeiam que a gente faça - Parte II)

Entretanto, deve-se ressaltar que a repressão e os estereótipos não possuem ação somente sobre o gênero feminino, atingindo também os homens. As matérias presentes no site mencionam somente a insegurança $\mathrm{e}$ as dúvidas das meninas, não considerando que os rapazes também ficam inseguros e possuem dúvidas relacionadas à sua vida afetivosexual.

Como um último ponto a ser analisado, deve-se destacar o fato do site aconselhar seus leitores, na falta de melhores fontes de informações, a procurar ajuda de alguém próximo, "querido" e em quem se confie. Dá como exemplos destas pessoas um professor, alguém mais velho, os pais ou, até mesmo, o pastor da igreja, como ilustrado na passagem abaixo transcrita: 
Se você não tem condições de procurar um terapeuta ou psicólogo, existe a possibilidade de pesquisar em um bom material de leitura (livros, $C D$ ROM, internet). Existem também serviços de orientação sexual por telefone como o Pró Sexo e o SOS Sexo. Mas não fique sem falar com ninguém, remoendo idéias ruins na cabeça. Sempre vale a pena procurar um professor querido, o pastor da sua igreja, um primo próximo, alguém mais velho, de quem você goste e em quem você confie. (Todo mundo tem fantasias sexuais)

É necessário atentar para as possíveis consequiências de uma observação como esta, uma vez que, dependendo da pessoa ou da qualidade do material de consulta procurado pelo adolescente, a situação pode agravar-se. Assim, como no exemplo acima transcrito, se um adolescente procurar o pastor de sua igreja para lhe contar uma fantasia sexual existem grandes possibilidades deste pastor, guiado pelas suas crenças religiosas, reprimir ainda mais algo que já é suficientemente confuso e perturbador para o jovem. É muito comum as orientações pautadas no senso comum incluírem crenças, idéias distorcidas, e acríticas e, além disso, sempre estão carregadas de valores que, em geral, não são questionados no momento em que a "ajuda" é oferecida. É provável, portanto, que

orientações leigas recebidas sobre as fantasias sexuais não proporcionem ao jovem o esclarecimento de que necessitam.

\section{CONCLUSÕES}

Tendo-se em vista as análises realizadas acerca do conteúdo do referido site, pode-se afirmar que o mesmo traz muitas visões distorcidas sobre a sexualidade, proporcionando uma orientação sexual que não promove uma reflexão crítica e de um conseqüente posicionamento político frente à temática. Conseqüentemente, não se pode alcançar, com informações como as contidas no referido site, uma vivência livre da sexualidade e desprovida de preconceitos e estereótipos.

$\mathrm{O}$ site abarca algumas questões importantes e, embora não as aprofunde e as mescle com visões estereotipadas, proporciona um primeiro contato com algumas temáticas. Entretanto, a amostra analisada aponta que o conteúdo tem caráter repressivo na exata medida em que as informações estão carregadas de valores, preconceitos e estereótipos que não são, em nenhum momento, questionados ou discutidos. Por exemplo, sabe-se que se trata de um site pretensamente voltado para o público feminino (considerando o nome igirl), e ao selecionar como seu conteúdo temas como moda, astrologia, beleza e sexualidade confirma uma determinada construção social dos papéis femininos.

Há algumas questões que dizem respeito à forma como o site está organizado que também parecem importantes, e que mereceriam maior atenção em um outro trabalho. Ele é dividido em diversas seções, o que acaba fazendo com que muitas informações acabem fragmentadas e, por vezes, contraditórias e incompletas, além de não se garantir que uma pessoa que tenha acesso a um determinado conteúdo tenha o mesmo acesso a outros, os quais se encontram muitas vezes relacionados, sendo, portanto, complementares. Não se dá destaque às diferenças e contradições entre as diversas visões que são apresentadas, o que reforça a idéia de fragmentação e não dá margem à confrontação e ao diálogo.

Os temas são tratados com superficialidade e em tons de "conselhos", embora haja brevíssimas opiniões de especialistas que, no entanto, encontram-se recortadas e interpretadas por quem escreve os artigos, o que muitas vezes acaba distorcendo ou, até mesmo, anulando a fala do profissional em questão. Além disso, as informações possuem um caráter de fornecimento de receitas prontas, de soluções para problemas que perturbam as adolescentes, não buscando promover reflexão, conscientização e posicionamento.

O que chama a atenção no site é o reforço que se faz de uma forma de repressão sexual que coloca a mulher como submissa e inferior ao homem, ou seja, algumas matérias fornecem dicas de como a garota deve se comportar para agradar e, assim, conseguir conquistar um homem, sendo que, quase sempre, esse comportamento está em concordância com os padrões socialmente impostos (considerados adequados e desejáveis).

Em suma, o fato de não se explicar o porquê da existência de determinados comportamentos, situações e idéias tidas como padrões sociais os coloca como naturais, não produzindo, portanto, reflexão e conscientização. Os adolescentes dos nossos dias estão acostumados com respostas prontas e encontram isso no site, que fornece dicas e conselhos de como se agir para atingir esta normatização imposta como sinônimo de felicidade. Algumas destas dicas até podem ser adequadas, mas o que se critica aqui é o não aproveitamento do espaço de comunicação para estimular a reflexão, que poderia proporcionar ao jovem uma postura mais crítica frente às diversas situações conflitivas que lhe são colocadas ao longo da vida, deixando assim esta postura passiva de aceitação de respostas fechadas para situações específicas que predomina entre a população jovem mundial.

Nesse sentido, a informação disponível e a forma como ela é apresentada no site refere-se a regras que reforçam a reprodução das estruturas de poder vigentes o que, como sabemos, é uma das facetas da repressão sexual. Atendendo aos modelos, são reproduzidos "padrões comportamentais", quando a idéia seria incentivar os jovens a exercitarem a reflexão e a autonomia sobre a sua sexualidade e a de outros, isto é, estimular para que se possa vivê-la de forma livre, responsável e prazerosamente. É fundamental o posicionamento crítico da Psicologia em relação aos veículos de orientação sexual para que estes possam, de fato, garantir o esclarecimento e a orientação ética e não meramente reproduzir padrões sociais relacionados ao que Marcuse (1956/1968) chamou de mais-repressão. Novas investigações nesse sentido poderiam contribuir neste debate. 


\section{Referências}

Azeredo, R. H. S. (1993). Identidade sexual. Em M. Ribeiro (Org.), Educação sexual: Novas idéias, novas conquistas (pp. 39-50). Rio de Janeiro: Rosa dos Tempos.

Becker, D. (1994). O que é adolescência. (Coleção Primeiros Passos, $\left.n^{\circ} 159\right)$. São Paulo: Brasiliense.

Bauer, M. W. \& Gaskell, G. (2003). Pesquisa qualitativa com texto, imagem e som: Um manual prático (2 $2^{\mathrm{a}} \mathrm{ed}$.). Petrópolis: Vozes

Cabral, J. T. (1995). A sexualidade no mundo ocidental. Campinas: Papirus.

Canella, P. R. B. (1984). Liberdade e repressão sexual. Em R. C. Cavalcanti \& N. Vitiello (Orgs.), Sexologia I (pp. 56-60). São Paulo: FEBRASGO.

Campos, D. M. S. (1986). Psicologia da adolescência: normalidade e psicopatologia (12 ${ }^{\mathrm{a}}$ ed.). Petrópolis: Vozes.

Chauí, M. (1985). Repressão sexual: Essa nossa (des)conhecida. São Paulo: Brasiliense.

Costa, M. (1986). Sexualidade na adolescência: Dilemas e crescimento. São Paulo: L\&PM Editores.

Fucs, G. B. (1998). Sexo sem vergonha. São Paulo: Gente.

Grossi, M. P. (1992). O masculino e o feminino na educação. Em E. P. Grossi (Org.), Paixão de aprender (pp. 252-258). Petrópolis: Vozes.

Guimarães, I. (1995). Educação sexual na escola: Mito e realidade. Campinas: Mercado das Letras.

Loyola, C. (1990). Sexualidade do adolescente. Em R. Cavalcanti (Org.), Saúde sexual e reprodutiva: Ensinando a ensinar (pp. 319-326). Brasília: CESEX.
Maia, A. C. B. (2001). Sexualidade: Reflexões sobre um conceito amplo. Scientific Journal SBPN (Sociedade Brasileira de Pesquisadores Nikkeis), 5(1), 45-48.

Marcuse, H. (1968). Eros e civilização: Uma interpretação filosófica do pensamento de Freud. Rio de Janeiro: Zahar Editores. Publicado originalmente em 1956.

Marcuse, H. (1998). Cultura e sociedade. Vol. 2. São Paulo: Paz e Terra. Publicado originalmente em 1965.

Nunes, C. A. (1987). Desvendando a sexualidade. Campinas: Papirus.

Paiva, V. (1989). Evas, Marias e Lilithis: As voltas do feminismo. São Paulo: Brasiliense.

Ribeiro, P. R. M. (1990). Educação sexual: Além da informação. São Paulo: EPU.

Silva, S. G. (1999). O conflito identitário: Sexo e gênero na constituição das identidades. Revista Brasileira de Sexualidade Humana, 10(1), 70-85.

Vitiello, N. (1995). A educação sexual necessária. Revista Brasileira de Sexualidade Humana, 6(1), 15-28.

Vitiello, N. (1997). Sexualidade: Quem educa o educador? São Paulo: Iglu.

Werebe, M. J. G. (1981). Educação sexual: Instrumento de democratização ou de mais repressão? Cadernos de Pesquisa, 36, 99-110.

Whitaker, D.C.A. (1995). Menino-Menina: Sexo ou gênero? Alguns aspectos cruciais. Em R. V. Serbino \& M. A. R. L. Grande. (Orgs.), A escola e seus alunos: O problema da diversidade cultural (pp. 31-52). São Paulo: Unesp.

Enviado: 16.01 .2004 Revisado: 08.03.2004 Aceito: 15.04.2004

\section{Sobre os autores:}

Giovana Bovo Facchini: Graduanda em Psicologia na Universidade Estadual Paulista "Júlio de Mesquita Filho" - Campus Universitário de Bauru (Unesp - Bauru) - Endereço eletrônico: gifacchini@yahoo.com.br

Ana Cláudia Bortolozzi Maia: Docente do Curso de Psicologia na Universidade Estadual Paulista "Júlio de Mesquita Filho" - Campus Universitário de Bauru (Unesp - Bauru) - Endereço eletrônico: bortolozzimaia@uol.com.br

Ari Fernando Maia: Docente do Curso de Psicologia na Universidade Estadual Paulista "Júlio de Mesquita Filho" - Campus Universitário de Bauru (Unesp - Bauru) - Endereço eletrônico: arifernando@uol.com.br 